\title{
Macroeconomic Dynamics and Modelling on Chinese Economy
}

\author{
Ling-Yun $\mathrm{He}^{1} \cdot$ Hua-Qing $\mathrm{Wu}^{2}$ \\ Published online: 8 May 2020 \\ (c) Springer Science+Business Media, LLC, part of Springer Nature 2020
}

Since adopting the reform and opening up policy in 1978, China has witnessed historic changes in domestic economy and society. At the same time, Chinese economy has been playing an increasingly significant role in the world. In 2019, China's GDP exceeds 14.4 trillion US dollars, and contributes around 30\% of global economic growth. It is also commented that the GDP of China has exceeded the USA in terms of purchase power parity in 2015 according to the IMF, and will eclipse the scale of the United States in terms of market exchange rates by 2030.

However, from the perspective of Chinese domestic economy, challenges of imbalance and insufficiency on the overall economic development are urgently needed to be faced, such as the risk of falling into "middle income trap", regional disparities, environmental pollutions, and income inequality. To achieve a healthy development in the 'New Era', the Chinese President Xi Jinping proposed that China's economy should turn from the rapid growth mode to the high-quality development mode. Accordingly, a series of polices with great impact have been lunched, including the Belt and Road Initiative, the innovational and greening development strategies, and so on. Even so, it is also uncertain for policy makers how effective these polices will be and to what extent the world economy will positively interact with Chinese economy in future. To respond to the requests and address these issues, it is very interesting and necessary to organize a conference and provide a forum for deeply discussing the above topics, especially by using dynamic modeling, forecasting methods and other quantitative tools. Therefore, we compiled the 11 papers from the contributions that enhance the existing computational methodologies and applications on China's economy in the "New Era", and provide valuable insights and implications for the practice of the world development. The topics of this collection focus heavily on the macroeconomic dynamics and modelling on the following issues in China:

Ling-Yun He

lyhe@amss.ac.cn

1 College of Economics, Jinan University, Guangzhou 510632, China

2 School of Economics, Hefei University of Technology, Hefei 230009, China 
- the evaluation methods and applications on Chinese's over-capacity and environmental efficiency in certain industries and regions, e.g., China's coal Industry;

- the forecasting methods and applications on the Chinese Belt and Road Initiative (BRI), e.g., trade potential, and energy saving and $\mathrm{CO}_{2}$ emissions reduction potential Under the BRI;

- the forecasting methods and applications on energy and carbon spot or futures prices.

We hope that our Special Issue might provide more perspectives and insights in the study of Chinese macroeconomy, and deepen the understandings of Chinese transitional economy.

Publisher's Note Springer Nature remains neutral with regard to jurisdictional claims in published maps and institutional affiliations. 